\title{
Continuing respiratory problems three and a half years after acute viral bronchiolitis
}

\author{
M S C WEBB, R L HENRY, A D MILNER, G M STOKES, AND A S SWARBRICK \\ Department of Child Health, Queen's Medical Centre, Nottingham
}

SUMMARY We reviewed the clinical progress of 81 children as part of a prospective study three and a half years after admission to hospital with acute viral bronchiolitis in infancy. Fifty six $(69 \%)$ reported episodes of lower respiratory symptoms continuing over the preceding year, 25 (31\%) had symptoms lasting for longer than two weeks on two or more occasions, $14(17 \%)$ had symptoms for more than 100 days, and six (7\%) required readmission to hospital with acute repiratory illness. Two years previously, these percentages had been $82 \%, 36 \%, 33 \%$, and $13 \%$ respectively. Forty six $(57 \%)$ children were said to be improving or to have become asymptomatic, but eight $(10 \%)$ were deteriorating. There was no difference in the personal or family history of atopy, nor in the rate of skin test positivity between those with and without continuing symptoms, suggesting that atopy does not play an important role in the persistence of symptoms. Less than half the symptomatic children had received bronchodilator treatment during the preceding 12 months.

It has been suggested that childhood respiratory illness may be a forerunner of chronic lung disease in adult life. ${ }^{1}$ Children who suffer acute bronchiolitis in infancy have a high incidence of respiratory problems in succeeding years, whether or not their initial illness was severe enough to require admission to hospital. ${ }^{2-4}$ They therefore provide a useful group for long term prospective follow up to test this hypothesis. With this in mind, we have recruited children admitted to hospital over the past five years, and have previously reported our findings at one year after acute bronchiolitis, ${ }^{5}$ when $50 \%$ had had episodes of wheezing and $75 \%$ had lung function abnormality, and at two years, ${ }^{6}$ by which time $75 \%$ had had episodes of wheezing and $82 \%$ had had appreciable lower respiratory tract illness. In this paper, we report on the continuing problems in a group of 81 children, three and a half years after their acute bronchiolitis.

There is still considerable uncertainty about the aetiological factors underlying the high incidence of post bronchiolitic symptoms. There is evidence that breast feeding, ${ }^{7}$ maternal smoking, ${ }^{8}$ and other social factors ${ }^{7}$ may influence the development of childhood respiratory problems, and there is continuing debate about whether an inherited abnormality of airways responsiveness predisposes to respiratory syncytial virus infection and bronchiolitis, or whether the virus itself creates bronchial hyperreactivity. Nor is the extent to which the interaction of atopy contributes to the initial illness and subsequent persistence of symptoms fully understood. In addition, therefore, we have attempted to throw further light on the role of this latter factor, atopy, by looking at the atopic status of these children in terms of personal and family history of atopic illness and their rate of skin test positivity to three common allergens.

\section{Patients and methods}

Eighty one children, all of whom had been admitted to hospital during winter epidemics of respiratory syncytial virus infection were studied. The criterion for entry into the study was a clinical diagnosis of acute bronchiolitis in a child with no previous history of similar illness, as evidenced by a brief prodrome of upper respiratory symptoms followed by rapid onset of cough, wheeze, tachypnoea, and poor feeding associated with hyperinflation, recession, and fine crepitations with or without rhonchi. ${ }^{9}$ The first 21 children enrolled for study and follow up were only those whose bronchiolitis was of sufficient severity to preclude oral feeding, but all subsequent admissions, irrespective of severity, were considered eligible. Forty one of 65 for whom results were 
obtained from nasopharyngeal aspirate were positive for respiratory syncytial virus by immunofluorescence or tissue culture, or both. Adenovirus type 1 was isolated in one child, and Haemophilus influenzae $s p$ in another. There were 42 boys and 39 girls, their mean age was 110 days (range 25 to 343 ) at admission and was 47 months (range 42 to 56) at follow up.

These children were reviewed as outpatients at a mean time of 43 months (range 40 to 48 ) after their acute illness. Details of upper and lower respiratory symptoms over the preceding year were obtained, with particular reference to frequency, duration, nature, and severity of symptoms and precipitating factors. Evidence of atopy (asthma, eczema, or hay fever) in the family was recorded, as were manifestations of atopy (eczema, rhinitis, or other reaction to environmental allergens) in the child. Physical examination (including height and weight) was performed.

Skin tests, using the epicutaneous prick method, were performed on the volar aspect of the forearm. ${ }^{10}$ Three Bencard test solutions were used-cat fur (solution no 3204), house dust mite (solution no 2801), and B2 grass pollens (solution no 4100 ) - plus a negative control (solution no 1908) and a positive control $(0 \cdot 1 \%$ histamine acid phosphate). The wheal diameter (if not circular, then the mean of the maximum diameter and that perpendicular to it), was measured at 15 minutes (12 minutes for histamine), and a reading of $3 \mathrm{~mm}$ or more was regarded as positive.

Statistical analysis was by Student's $t$ test and $\chi^{2}$ analysis using Yates's correction. The study was approved by the local ethical committee, and informed parental consent was obtained.

\section{Results}

Fifty six children $(69 \%)$ had had lower respiratory symptoms during the 12 months before follow up, 48 $(59 \%)$ having had at least one episode of wheezing (Table 1). Six children $(7 \%)$ had required admission to hospital with acute lower respiratory illness.

Of the 56 children with persisting symptoms who had visited their general practitioners a mean of 3.8 times for lower respiratory problems (eight had made more than eight visits), $27(48 \%)$ had received antibiotics, $26(46 \%)$ bronchodilators, $25(45 \%)$ cough medicines, three $(5 \%)$ were taking regular sodium cromoglycate, and four ( $7 \%$ ) had been given no treatment of any sort. Thirty children $(54 \%)$ were reported to be improving with time, $16(29 \%)$ were continuing unchanged, but nine $(16 \%)$ were getting worse. The parents of one child were unable to comment upon her progress.

There were no significant differences between those children with continuing lower respiratory symptoms ('chesty') and those who were healthy, ('healthy'), in respect of age at admission, sex ratio,

Table 1 Incidence of reported lower respiratory tract symptoms in 81 children during the 12 months period between $2^{1 / 2}$ and $31 / 2$ years after acute bronchiolitis. (Figures in square brackets represent percentages of 55 children with symptoms up to 2 years after initial attack of acute bronchiolitis ${ }^{6}$ )

\begin{tabular}{|c|c|c|c|c|c|c|c|}
\hline & \multicolumn{3}{|c|}{ Positive } & \multicolumn{2}{|c|}{ Negative } & \multicolumn{2}{|c|}{ Unclear } \\
\hline & No & $(\%)$ & {$[\%]$} & No & $(\%)$ & No & $(\%)$ \\
\hline Any episode of wheeze & 48 & $(59)$ & {$[71]$} & 31 & (39) & 2 & (2) \\
\hline Any lower respiratory symptoms & 56 & (69) & {$[-]$} & 23 & (29) & 2 & (2) \\
\hline Lower respiratory illness for more than 2 weeks or any episode & & & & & & & \\
\hline of wheeze, or both & 51 & $(63)$ & {$[82]$} & 28 & $(35)$ & 2 & $(2)$ \\
\hline Two or more episodes of cough or wheeze, or both, lasting more than 2 weeks & 25 & (31) & {$[36]$} & 55 & (68) & 1 & (1) \\
\hline Readmission to hospital with lower respiratory symptoms & 6 & (7) & {$[13]$} & 75 & (93) & 0 & (0) \\
\hline
\end{tabular}

Table 2 Personal and family history of atopy

\begin{tabular}{|c|c|c|c|c|c|c|c|}
\hline & \multicolumn{2}{|c|}{$\begin{array}{l}\text { Whole group } \\
(n=81)\end{array}$} & \multicolumn{2}{|c|}{$\begin{array}{l}\text { 'Chesty' } \\
(n=56)\end{array}$} & \multicolumn{2}{|c|}{$\begin{array}{l}\text { 'Healthy' } \\
(n=25)\end{array}$} & $x^{2}$ \\
\hline Eczema & 25 & $(31)$ & 18 & (32) & 7 & (28) & NS \\
\hline Eczema, or perennial/seasonal rhinitis, or allergies & 51 & $(63)$ & 35 & (63) & 16 & (64) & NS \\
\hline 1st degree relative with asthma & 22 & $(27)$ & 15 & (27) & 7 & $(28)$ & NS \\
\hline 1st degree relative with asthma, eczema, or hayfever & 36 & (44) & 23 & (41) & 13 & $(52)$ & NS \\
\hline
\end{tabular}

NS=not significant. 
Table 3 Skin test positivity (positive $\geqslant 3 \mathrm{~mm}$ wheal diameter)

\begin{tabular}{lllllllll}
\hline & \multicolumn{2}{l}{$\begin{array}{l}\text { Whole group } \\
(n=81)\end{array}$} & \multicolumn{2}{l}{$\begin{array}{l}\text { CChesty' } \\
(n=56)\end{array}$} & \multicolumn{2}{l}{$\begin{array}{l}\text { 'Healthy' } \\
(n=25)\end{array}$} \\
& No & $(\%)$ & No & $(\%)$ & No & $(\%)$ & \\
\hline House dust mite & 11 & $(14)$ & 7 & $(13)$ & 4 & $(16)$ & NS \\
Any one of three & 12 & $(15)$ & 8 & $(14)$ & 4 & $(16)$ & NS \\
Any two of three & 4 & $(5)$ & 4 & $(7)$ & 0 & $(0)$ & NS \\
\hline
\end{tabular}

NS=not significant.

proportion with respiratory syncytial virus, age at follow up, and height and weight centiles. Similarly, there was no difference in personal or family history of atopy (Table 2 ), nor in skin sensitivity (Table 3 ). Thirty five $(64 \%)$ mothers whose children were in the 'chesty' group were active smokers or had ceased less than one year previously compared with nine $(36 \%)$ with children in the 'healthy' group. This difference reached statistical significance at the $5 \%$ level.

Upper respiratory tract infection was a precipitating factor in $54(96 \%)$ children, and the sole precipitant in $19(34 \%)$. Exercise and climatic variables were said to be responsible for symptoms in $26(46 \%)$ and $23(41 \%)$ children respectively, with a further nine $(11 \%)$ claiming other agents such as emotional upset and contact with animals.

\section{Discussion}

We have shown a continuing high incidence of lower respiratory problems three and a half years after acute viral bronchiolitis in infancy, with only a moderate reduction compared with one and a half years earlier. ${ }^{6}$ Our figure of $59 \%$ who had wheezed at some time during the preceding year is higher than the $38 \%$ during the first four years and the $42 \%$ at any time in the 10 years after infection reported by Pullan and Hey, ${ }^{2}$ and higher also than Mok and Simpson's $47 \%$ (94 out of 200 ) who had had wheezing at any time during the seven years after infection. ${ }^{3}$ These data reinforce our previous suggestion $^{6}$ that earlier authors may well have underestimated considerably the frequency of symptoms during the first few years after bronchiolitis due to poor parental recall for events of three to six years beforehand.

We have been unable to recruit normal healthy 2 to 3 year olds as controls for this long term, prospective, follow up study, though this should be possible by age 5 to 6 years. Without recourse to comparisons with such a group, we are reluctant to draw firm conclusions from our data, but feel that certain points are worth making. Our incidence of approximately $50 \%$ of all children with a personal history of eczema, rhinitis, or allergies, and a similar figure with a first degree relative with asthma, eczema, or hayfever seems high but is very similar to that found in a control population by Pullan. ${ }^{11}$ When subdivided into those with and without continuing symptoms, there is no difference between the subgroups. A more precise way of looking at atopy must be to study skin sensitivities. We have found a low degree of positivity overall, again with absolutely no difference between the 'chesty' and 'healthy' subgroups, and all results were significantly lower than those of a group of hospital based asthmatics of the same age (unpublished data). In other words, there was no apparent relation between atopy and either the bronchiolitis attack or the continuing symptoms thereafter. These interrelations have been looked at before: Mok and Simpson, ${ }^{12}$ who determined atopic status on the basis of personal or family history alone, concluded that both atopy and bronchial reactivity, while not themselves closely related, may contribute independently to the persistence of symptoms. The independent occurrence of these two parameters had already been shown by Sibbald et al, ${ }^{13}$ who suggested that the presence of atopy increased the likelihood of bronchial hyper-reactivity being expressed clinically. Laing et $\mathrm{l}^{14}$ proposed that atopy predisposed to acute bronchiolitis during an epidemic of respiratory syncytial virus, but our figure of $12(15 \%)$ of the whole group with any one positive skin test is at considerable variance with their $45 \cdot 2 \%$, and closer to their control of $12.5 \%$. Our lower level of skin sensitivity, showing no difference between those with and without continuing symptoms, tends to agree more with Sims $e t$ $a l,{ }^{15}$ who concluded that atopy does not predispose to respiratory syncytial virus bronchiolitis, or post bronchiolitic wheezing. It is this conclusion that we feel is most likely to be correct.

Despite recent increasing awareness of the nature and under treatment of recurrent wheezing and lower respiratory episodes, ${ }^{16}{ }^{17}$ the relatively low percentage of symptomatic children who had been prescribed a bronchodilator was disappointing, especially as many of those for whom we had suggested intermittent bronchodilator treatment when seen one and a half years previously had not had this treatment continued, despite apparent initial benefit. Although most of our children were improving and the later follow up studies of both Mok and Simpson $^{3}$ and Pullan and Hey ${ }^{2}$ suggest that this improvement will continue, the need for sustained vigilance on this issue is clear.

Of all the parameters studied, maternal smoking was the only positive correlation with continuing 
chestiness after bronchiolitis. Our study does not enable us to distinguish between passive smoking per se and other socioenvironmental factors related to smoking, though these are clearly important as described thoroughly by Pullan et al. ${ }^{7}$

In conclusion, we have shown a persisting high incidence of lower respiratory symptoms three and a half years after acute bronchiolitis, with more than $50 \%$ of children still affected. Atopy does not seem to play an important role.

We thank the children, their parents, and Professor D Hull, Dr $P$ Barbor, Dr D Johnston, and Dr N Rutter who allowed us to study patients under their care. Financial support was gratefully received from the Asthma Research Council.

\section{References}

${ }^{1}$ Burrows B, Lebowitz MD, Knudson RJ. Epidemiological evidence that childhood problems predispose to airways disease in the adult. Pediatr Res 1977;11:218-20.

2 Pullan CR, Hey EN. Wheezing, asthma and pulmonary dysfunction 10 years after infection with respiratory syncytial virus in infancy. $B r$ Med $J$ 1982;284:1665-9.

${ }^{3}$ Mok JYQ, Simpson $H$. Outcome of acute lower respiratory tract infection in infants: preliminary report of seven-year follow-up study. $\mathrm{Br}$ Med J 1982;285:333-7.

${ }^{4}$ McConnochie KM, Roghmann KJ. Bronchiolitis as a possible cause of wheezing in childhood: new evidence. Pediatrics 1984;74:1-10.

5 Stokes GM, Milner AD, Hodges IGC, Groggins RC. Lung function abnormalities after acute bronchiolitis. $J$ Pediatr 1981;98:871-4.
' Henry RL, Hodges IGC, Milner AD, Stokes GM. Respiratory problems two years after acute bronchiolitis in infancy. Arch Dis Child 1983;58:713-6.

7 Pullan CR, Toms GL, Martin AJ, Gardner PS, Webb JKG, Appleton DR. Breast feeding and respiratory syncytial virus infection. Br Med J 1980;281:1034-6.

${ }^{8}$ Fergusson DM, Horwood LJ, Shannon FT. Parental smoking and respiratory illness in infancy. Arch Dis Child 1980;55: 358-61.

${ }^{9}$ Henry RL, Milner AD, Stokes GM. Bronchiolitis (letter). Am J Dis Child 1983;137:805-6.

10 Tipton WR. Evaluation of skin testing in the diagnosis of IgE-mediated disease. Pediatr Clin North Am 1983;30:785-93.

1 Pullan CR. Respiratory syncytial virus infection-epidemiology and follow-up. (Thesis). Newcastle:University of Newcastle upon Tyne, 1984.

12 Mok JYQ, Simpson H. Symptoms, atopy and bronchial reactivity after lower respiratory infection in infancy. Arch Dis Child 1984;59:299-305.

13 Sibbald B, Horn MEC, Brain EA, Gregg I. Genetic factors in childhood asthma. Thorax 1980;35:671-4.

14 Laing I, Riedel F, Yap PL, Simpson H. Atopy predisposing to acute bronchiolitis during an epidemic of respiratory syncytial virus. $\mathrm{Br}$ Med $J$ 1982;284:1070-2.

15 Sims DG, Gardner PS, Weightman D, Turner MW, Soothill JF. Atopy does not predispose to RSV bronchiolitis or postbronchiolitic wheezing. $\mathrm{Br}$ Med J 1981;282:2086-8.

16 Anderson HR, Bailey PJ, Palmer J, West S. Community survey of the drug treatment of asthma and wheezing in children. Thorax 1981;36:222-3.

17 Speight ANP, Lee DE, Hey EN. Underdiagnosis and undertreatment of asthma in childhood. Br Med J 1983;286:1253-6.

Correspondence to Professor A D Milner, Department of Child Health, Queen's Medical Centre, Nottingham NG7 2UH.

Received 6 June 1985 